\title{
MENSTRUAL PROBLEM AMONG ADOLESCENT GIRLS REGARDING SCHOOL ABSENTEEISM- A CROSS- SECTIONAL STUDY
}

\author{
Hemalatha $K^{1}$, S. Shruthi ${ }^{2}$
}

${ }_{1}^{1}$ Associate Professor, Department of Obstetrics and Gynaecology, Madras Medical College, Chennai, Tamilnadu.

${ }^{2}$ Assistant Professor, Department of Obstetrics and Gynaecology, Government Chengalpattu Medical College and Hospital,

Chengalpattu, Tamilnadu.

\section{ABSTRACT}

\section{BACKGROUND}

Menstrual problems in adolescent girls are very common in this age group. Identification of abnormal menstrual problems is essential and correction is needed. In this study, we have attempted to study the frequency of menstrual problems and its impact on school and college attendance.

\section{MATERIALS AND METHODS}

In this study, 300 girls in the age group of 14 - 19 years who attained menarche were non-randomly selected for convenience. This study was carried out in a school and three colleges in Chengalpattu. Many criteria were applied and critically analysed.

\section{RESULTS}

Dysmenorrhoea was the commonest menstrual problem noticed, followed by irregular cycle pattern. There was a statistically significant association between school absenteeism and menstrual disorders.

\section{CONCLUSION}

Adolescent girls school health programme should include a provision for screening of adolescent girls for menstruation related problems, clearing misconception and offer them possible treatment options.

\section{KEY WORDS}

Adolescent Girl, Menstrual Problem, Dysmenorrhoea, Oligomenorrhoea.

HOW TO CITE THIS ARTICLE: Hemalatha K, Shruthi S. Menstrual problem among adolescent girls regarding school absenteeisma cross-sectional study. J. Evolution Med. Dent. Sci. 2018;7(21):2527-2530, DOI: 10.14260/jemds/2018/568

\section{BACKGROUND}

According to WHO, the period of adolescence ranges from 10 to 19 years. The adolescent group comprises of one-fifth of the total population of the world. In India, about $21.4 \%$ of the population falls in this age group.

It is a phase of rapid physical growth and development along with physiological growth and behavioural maturity. This period needs special attention because an adolescent faces different problems during development, different circumstances in school and college.

Menarche, the first menstrual period of life is a milestone in female puberty that signifies the maturation of reproduction potential. Age of onset varies from 9 years to 18 years. In India, it is reported to be around 12 years.

The average age of menarche is around 13 years 6 months. The length of menstrual cycle is usually of $21-35$ days from first day of menstrual period. The duration of bleeding is about 3 - 5 days and blood loom is between 30 $80 \mathrm{~mL}$. Cycle is often irregular in the beginning due to immature Hypothalamic Pituitary axis, but by the age of 17 18 years menstrual cycle becomes regular.

'Financial or Other Competing Interest': None.

Submission 24-04-2018, Peer Review 08-05-2018,

Acceptance 11-05-2018, Published 21-05-2018.

Corresponding Author:

Dr. Hemalatha $K$,

Associate Professor,

Department of Obstetrics and Gynaecology,

Madras Medical College,

Chennai, Tamilnadu.

E-mail: drlathababu2017@gmail.com

DOI: $10.14260 /$ jemds $/ 2018 / 568$
Adolescents face so many problems during menstruation, mainly dysmenorrhoea. It is a common problem, yet it is not taken when assessing adolescent health.

Dysmenorrhoea is defined as difficult menstrual flow or painful menstruation. About $50 \%-75 \%$ of young girls complain of this, which constitutes leading cause of school absenteeism.

In addition to pain, irregular flow and premenstrual mood swings, the cultural menstrual taboos, messages like menstruation is shameful or dirty or something intimidating have direct or indirect influence on school absenteeism too.

The menstrual cycle is a very important indicator of women's reproductive health and their endocrine function. Some of these menstrual characteristics are such as irregularity in the menstrual cycle, premenstrual pain and discomfort and heavy menstrual discharge. Menstrual disturbances are common among the adolescent age group and are often explained by the immaturity of the hypothalamic - pituitary - gonadal axis. Identification of abnormal menstrual pattern through adolescence may permit early identification of potential health concerns for adulthood and future obstetric outcome of these young girls.

\section{Objective}

In this study, we have attempted to study the frequency of menstrual problems and its impact on school and college attendance.

\section{MATERIALS AND METHODS}

The population comprised of 300 girls in the age group of 1419 years who attained menarche and were randomly selected for the study for convenience by using pretested and 
predesigned questionnaire. This study was carried out in a school and three colleges in Chengalpattu.

\section{Inclusion Criteria}

Girls in the age group of 14 to 19 years, who had attained menarche.

\section{Exclusion Criteria}

1. Girls with primary amenorrhoea.

2. Girls who are married and/or pregnant.

Data was collected by personal interviews with a pretested and predesigned questionnaire. Questionnaire comprised age, socioeconomic status, educational status, menarchal age, menstrual pattern, premenstrual symptoms, dysmenorrhoea, impact of menstrual disorders on school attendance and consultation for menstrual problem. The collected data was analysed, and results interpreted. Proforma with standard questions given and asked the students.

\section{Statistical Analysis}

SPSS version 16 was used for data analysis. Quantitative variables were expressed in frequency and percentages. Chisquare test is used for testing the association between qualitative variables. P-value $<0.05$ is considered as significant.

\section{RESULTS}

In the present study, girls of 300 in number in the age group of 14 - 19 yrs. who attained menarche were randomly selected for study. The study was analysed in various parameters.

\begin{tabular}{|c|c|c|}
\hline Age Group & Number & \% \\
\hline 14 & 48 & 16.0 \\
\hline 15 & 39 & 13.0 \\
\hline 16 & 33 & 11.0 \\
\hline 17 & 21 & 7.0 \\
\hline 18 & 72 & 24.0 \\
\hline 19 & 87 & 29.0 \\
\hline Total & $\mathbf{3 0 0}$ & $\mathbf{1 0 0 . 0}$ \\
\hline \multicolumn{2}{|c|}{ Table 1. Age Distribution of Participants } \\
\hline
\end{tabular}

Majority $53 \%$ of girls were in the age group of 18 - 19 years. $18 \%$ were in the age group of $16-17$ years. $29 \%$ were in the age group of $14-15$ years.

\begin{tabular}{|c|c|c|}
\hline Age at Menarche (Year) & Number & Percent \\
\hline 11 & 48 & 16.0 \\
\hline 12 & 139 & 46.3 \\
\hline 13 & 56 & 18.7 \\
\hline 14 & 36 & 12.0 \\
\hline 15 & 13 & 4.3 \\
\hline 16 & 8 & 2.7 \\
\hline Total & 300 & 100.0 \\
\hline
\end{tabular}

Mean age at menarche in our study was 12.5 years (1.18 SD).

\begin{tabular}{|c|c|c|}
\hline BMI & Number & Percent \\
\hline Underweight & 120 & 40.0 \\
\hline Normal & 108 & 36.0 \\
\hline Overweight & 54 & 18.0 \\
\hline Obese & 16 & 5.3 \\
\hline Morbidly obese & 2 & 0.7 \\
\hline Total & $\mathbf{3 0 0}$ & $\mathbf{1 0 0 . 0}$ \\
\hline \multicolumn{2}{|c|}{ Table 3. Distribution according to BMI }
\end{tabular}

Among 300 girls, 45\% were underweight.

$36 \%$ were normal weight.

$18 \%$ were overweight.

$5.3 \%$ were obese.

$0.7 \%$ were morbidly obese.

\begin{tabular}{|c|c|c|}
\hline Cycle Length & Number & Percentage \\
\hline Less than 21 & 12 & 4 \\
\hline $22-35$ & 231 & 77 \\
\hline $36-90$ & 48 & 16 \\
\hline Above 90 & 9 & 3 \\
\hline Total & 300 & 100 \\
\hline
\end{tabular}

$77 \%$ of the girls had cycle length of 22 - 35 days. $4 \%$ had cycle length of less than 21 days.

$16 \%$ had cycle length of 36 - 90 days.

$3 \%$ had cycle length of more than 90 days.

\begin{tabular}{|c|c|c|}
\hline Cycle Regularity & Number & Percentage \\
\hline Regular & 231 & 77.0 \\
\hline Irregular & 69 & 23.0 \\
\hline Total & $\mathbf{3 0 0}$ & $\mathbf{1 0 0}$ \\
\hline \multicolumn{2}{|c|}{ Table 5. Menstrual Cycle Regularity } \\
\hline
\end{tabular}

$77 \%$ of girls had regular menstrual cycle.

$23 \%$ of girls had irregular menstrual cycle.

\begin{tabular}{|c|c|c|c|c|c|c|c|c|c|}
\hline & \multicolumn{4}{|c|}{ Absence } & \multirow{2}{*}{\multicolumn{2}{|c|}{ Total }} & \multirow{3}{*}{$\begin{array}{l}\text { Chi- } \\
\text { Square }\end{array}$} & \multirow{3}{*}{$P$ value } \\
\hline & & \multicolumn{2}{|c|}{ Yes } & \multicolumn{2}{|c|}{ No } & & & & \\
\hline & & Number & Percent & Number & Percent & Number & Percent & & \\
\hline \multirow{2}{*}{ Dysmenorrhoea } & Yes & 51 & 17 & 144 & 48 & 195 & 65 & \multirow{2}{*}{3.93} & \multirow{2}{*}{$<0.001$} \\
\hline & No & 39 & 13 & 66 & 22 & 105 & 35 & & \\
\hline \multirow{2}{*}{$\begin{array}{c}\text { Premenstrual } \\
\text { Symptoms }\end{array}$} & No & 24 & 8 & 123 & 41 & 147 & 49 & \multirow{2}{*}{25.66} & \multirow{2}{*}{$<0.001$} \\
\hline & Yes & 66 & 22 & 87 & 29 & 153 & 51 & & \\
\hline \multicolumn{2}{|l|}{ Total } & 90 & 30 & 210 & 70 & 300 & 100 & & \\
\hline
\end{tabular}

Highly significant association between the menstrual problems and school children ( $\mathrm{P}$ value $<0.001$ ).

The present study conducted among 300 adolescent girls to study the problem related to menstruation among adolescent girls and its impact on school and/ or college attendance. 


\section{Age Distribution}

- $\quad$ The study was conducted among girls of the age 14 to 19 years. 53\% were in the age group of 18 - 19 years.

- $18 \%$ were in the age group of $16-17$ years.

- $29 \%$ of them were in the age group of $14-15$ years.

- Mean age of the participants was 16.97 years (1.87 SD).

\section{Educational Status}

The study subjects were school and UG students. Maximum number of participants were $1^{\text {st }}$ and $2^{\text {nd }}$ year undergraduate students (53\%).

\section{Socioeconomic Status}

In our study, majority of the girls (65\%) belonged to SE class 1 and 2.

\section{BMI}

In our study, $40 \%$ of the participants were underweight and $5.3 \%$ of them were obese. Though majority of girls belonged to higher status, there was increased prevalence of underweight among the study subjects.

\section{Age at Menarche}

The mean age at menarche in our study was 12.5 years $(1.18$ SD). The mean age at menarche reported by other studies in India were 12.85 years,(1) 12.5 yrs.,(2) which correlates with our study.

\section{Menstrual Pattern and Problem}

- In our study, $77 \%$ of the girls had regular menstrual cycles and $23 \%$ had irregular menstrual cycles. Prevalence of irregular cycles reported by other studies

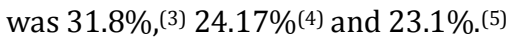

- $6 \%$ of the girls had hypomenorrhoea- menses less than 2 days.

- $\quad 83 \%$ of girls had bleeding for 3 - 7 days.

- $11 \%$ had menorrhagia - bleeding > 7 days which is similar to study conducted by Sharma et al(3) with $4.8 \%$ having bleeding for less than 2 days and 14.9\% with bleeding $>7$ days.

- Dysmenorrhoea was the menstrual problem reported by $65 \%$ of the girls with other studies showing prevalence of $67.2 \%{ }^{(3)}$ and $68.7 \% .{ }^{(6)}$

\section{DISCUSSION}

Other studies have shown the prevalence ranging from $27.9 \%$ to $74.3 \% .51 \%$ of the girls had one or the other symptoms of premenstrual syndrome, which is similar to the prevalence in the study by Samia Tabassum et al (53\%)(7) and Christina John (45.8\%).(8) The commonest symptom reported by our subjects were Abdominal bloating (23\%), Depression (14\%), Anxiety (12\%), Irritability (11\%), Breast tenderness (9\%), Fatigue (5\%) and Headache (3\%). Other studies have shown the prevalence of PMS 67.2\% and 74.3\%.(9) Oligomenorrhoea was the commonest type of irregularity (16\%) prevalent among the study subjects, which correlate with the study conducted by Mohite RV et al(10) and Anupriya et al(5) showing prevalence of $16.08 \%$ and $15.3 \%$. Other studies have shown prevalence ranging from $1.2 \%{ }^{(8)}$ to $19.3 \%$.(11)

Followed by polymenorrhoea (4\%), which correlates with study conducted by Sasritha Agarwal et al with $3.6 \%$ of girls reporting polymenorrhoea and $3 \%$ of girls had secondary amenorrhoea which is similar to study by Karout et al(11) with prevalence of $5.1 \%$; $30 \%$ of girls were absent to school or college due to menstrual problems like dysmenorrhoea and PMS despite $65 \%$ of girls having dysmenorrhoea only $8 \%$ had consulted physician for treatment.

There was statistically significant association between school absenteeism and menstrual disorder ( $\mathrm{P}$ value $<0.001 \%$ ).

Among these, dysmenorrhoea and premenstrual symptoms had a significant effect on academic performance and was responsible for school absenteeism.

\section{CONCLUSION}

1. As the problems related to menstruation were quite frequent and often resulted in interruption of daily routine of adolescent girls, school health programmes should include a provision for screening menstrual problems and provide them relevant information and treatment options.

2. Proper education about menstruation and related problems is important for both adolescent girls and their mothers to prevent avoidance of health care.

3. In spite of high prevalence of menstrual problems among the adolescents, the percentage of girls seeking physician consultation is very low.

4. Pain is often neglected by women, who consider pain as normal part of menstrual cycle.

5. This may help in improving school attendance rates and academic performance of the girl students.

\section{REFERENCES}

[1] Thakre SB, Thakre SS, Reddy M, et al. Menstrual hygiene: knowledge and practice among adolescent school girls of Saoner, Nagpur District. Journal of Clinical and Diagnostic Research 2011;5(5):1027-33.

[2] Singh A, Kiran D, Singh H, et al. Prevalence and severity of dysmesorrhoea: a problem related to menstruation, among first and second year female medical students. Indian J Physiol Pharmacol 2008;52(4):389-97.

[3] Sharma P, Malhotra C, Taneja DK, et al. Problems related to menstruation amongst adolescent girls. Indian J Paediatr 2008;75(2):125-9.

[4] Karthiga V, Boratne AV, Datta SS, et al. Menstrual problems and pattern of consultation among adolescent school girls in Pondicherry. Indian Journal of Medical Specialities 2011;2(2):92-5.

[5] Agarwal A, Venkat A. Questionnaire study on menstrual disorders in adolescent girls in Singapore. J Paediatr Adolesc Gynaecol 2009;22(6):365-71.

[6] Chan SS, Yiu KW, Yuen PM, et al. Menstrual problems and health seeking behaviour in Hong Kong Chinese girls. Hong Kong Med J 2009;15(1):18-23.

[7] Tabassum S, Afridi B, Aman Z, et al. Premenstrual syndrome: frequency and severity in young college girls. J Pak Med Assoc 2005;55(12):546-9.

[8] John C. A study of menstrual problems in adolescent girls. Retrieved on 28.7.11 from www.imakmj.com.

[9] Santina T, Wehbe N, Ziade F. Exploring dysmenorrhoea and menstrual experiences among Lebanese female adolescents. East Mediterr Health J 2012;18(8):857-63. 


\section{Jemds.com}

[10] Mohite RV, Mohite VR, Kumbhar SM, et al. Common menstrual problems among slum adolescent girls of western Maharashtra, India. JKIMSU 2013;2(1):89-97.
Original Research Article

[11] Karout N, Hawai SM, Altuwaijri S. Prevalence and pattern of menstrual disorders among Lebanese nursing students. East Mediterr Health J 2012;18(4):346-52. 